\title{
BIOÉTICA Y RELIGIÓN CRISTIANO-CATÓLICA: DOS RACIONALIDADES COMPLEMENTARIAS
}

\author{
Francisco Javier León Correa*
}

\begin{abstract}
Resumen: Desde un primer momento de confrontación, se está llegando a la convicción de que es necesario un diálogo fecundo entre bioética y religión, tal como lo reflejan distintos autores en estos últimos años. Por una parte, en el ámbito católico se ha profundizado en las relaciones entre religión y ciencia, entre fe y razón. Por otra, desde lo secular se reconoce interés en descubrir la óptima aportación de la teología moral al debate bioético, para generar un diálogo constructivo acerca de los aspectos éticos de la atención de la salud y el cuidado de la vida humana en el ámbito biomédico.

Después de examinar distintas posiciones, este artículo hace hincapié en el diálogo constructivo y en la probable aportación de la filosofía y la teología cristianas a la bioética.
\end{abstract}

Palabras clave: bioética, religión, diálogo

\section{BIOETHICS AND CHRISTIAN-CATHOLIC RELIGION: TWO COMPLEMENTARY RATIONALITIES}

\begin{abstract}
After a first moment of confrontation, in the last years several authors are coming to the conviction that a fruitful dialogue is necessary between bioethics and religion. On one hand, Catholic thinkers have reflected on the relations between science and religion and faith and reason. On the other hand, secular thinkers have expressed interest in discovering the optimal moral theology contribution to bioethical debate, in order to generate a constructive dialogue over ethical aspects of health care and the care of human life in the biomedical field.

After examining different positions, this article emphasizes constructive dialogue and the probable contribution to bioethics of Christian theology and philosophy.
\end{abstract}

Key words: bioethics, religion, dialog

\section{BIOÉTICA E RELIGIÂO CRISTÃ-CATÓLICA: DUAS RACIONALIDADES COMPLEMENTARES}

Resumo: Desde o primeiro momento de confrontação, tem-se a convicção de que se faz necessário um diálogo fecundo entre bioética e religião, assim como se reflete em diversos autores dos últimos anos. Por um lado, no âmbito católico, se tem aprofundado as relações entre religião e ciência, entre fé e razão. Por outro, secularmente reconhece-se interesse no aporte de elementos da teologia moral ao debate bioético, para gerar um diálogo construtivo acerca dos aspectos éticos da atenção à saúde e ao cuidado da vida humana no âmbito biomédico. Depois de examinar diversos posicionamentos, este artigo propóe um diálogo construtivo e o possível aporte da filosofía e da teologia cristãs à bioética.

Palavras-chave: bioética, religião, diálogo

* Doctor en Filosofía. Profesor Adjunto del Centro de Bioética, Facultad de Medicina, Pontificia Universidad Católica de Chile, Chile. Correspondencia: gibioetica@vtr.net 


\section{Introducción:}

La bioética es un diálogo plural entre diversas ciencias y entre las diferentes corrientes de pensamiento presentes en la sociedad acerca de los aspectos éticos de la atención en salud y el cuidado de la vida humana en el ámbito biomédico. Parte de los que participan en el diálogo lo hacen sin dialogar: algunos piensan que la luz de la fe resuelve ya los problemas planteados a la razón y el sentido moral del hombre y, por tanto, ya está preestablecida la solución a los dilemas éticos; otros, en cambio, sostienen que la religión y, más ampliamente, el mundo de las creencias, afectos y sentimientos, estorba y entorpece la reflexión, es irracional y debe dejarse fuera del estricto diálogo bioético.

El diálogo es posible si, por un lado, se reconoce el aporte de la ética cristiana a la bioética y, por otro, se respeta la diversidad de racionalidades y cosmovisiones presentes en la sociedad.

\section{Distintas visiones de la relación bioética- religión en el mundo posmoderno actual}

Una parte de la bioética norteamericana se ha presentado como un intento de conseguir una ética de consenso, basada en principios emanados de un "sentido común moral", que debe estar cerrado necesariamente a la trascendencia -aunque lo esté en ocasiones- y en la cual los interlocutores debieran dejar de lado sus creencias y convicciones religiosas o morales a favor de lograr acuerdos de mínimos(1).

Por ejemplo, Max Charlesworth, en su conocida obra "La bioética en una sociedad liberal", comenta que sólo podemos ponernos de acuerdo en que no vamos a ponernos de acuerdo y critica que no se deje a los individuos elegir su propia muerte, que se limite el arriendo de úteros en la fecundación in vitro o que "el enfoque utilitarista de coste-beneficio adoptado en el presente por muchos economistas sanitarios, burócratas y políticos (enfoque que se presta al paternalismo burocrático y el 'dirigismo') va(ya) directamente en contra de estos valores neoliberales. Por lo tanto, todavía existen dudas, pasos hacia atrás e incoherencias en el reconocimiento y la aceptación de los valores liberales en la bioética, con reliquias de criterios antiguos respecto de las cosas, como cuando el Estado se consideraba como refuerzo de la moralidad pública básica (...)”. Sostiene que "...en una sociedad liberal, la única moralidad común o consenso ético posible sería aquel fundado en los valores liberales primarios (autonomía moral, igualdad y justicia basadas en la autonomía y sus valores anexos). En dicha sociedad no puede haber ningún consenso sobre valores de segundo orden, 'parciales' o confesionales" (2). Se critica el "paternalismo" y el relativismo del utilitarismo y, a la vez, se rechaza todo intento de introducir cualquier valor de tipo religioso o moral en el espacio público.

H. Tristam Engelhardt comenta: "Las diferencias entre las visiones morales (entre ateos o creyentes o también entre los mismos ateos) son reales, fundamentan concepciones sustancialmente diferentes de la bioética y tienen su origen en que los participantes en las controversias morales disponen de premisas y de reglas de evidencia diferentes, de tal modo que las controversias no se pueden resolver por medio de argumentos racionales lógicos, ni mediante la apelación a una autoridad moral reconocida por todos. Sólo la moralidad secular general carente de contenido puede salvar este abismo y permitir la colaboración cuando no se alcanza la concurrencia de pareceres morales dotados de contenido"(3). Por eso puede compatibilizar su personal moral cristiana ortodoxa -que comparte con sus "amigos morales" - con su posición secular liberal, de ética de consenso, cuando actúa como un ciudadano más entre "extraños morales".

Se da la paradoja de que muchos de los impulsores de la bioética han partido desde distintas posiciones de fe(4): protestantes y católicos en Estados Unidos, en el Hasting Center de New York o en el Kennedy Institut dentro de la Georgetown University de Washington, dirigida por los jesuitas. Más aún, el primer Centro de Bioética en Europa fue el Instituto Borja de Bioética (en Cataluña), de los jesuitas, y es conocida la labor que han desarrollado en bioética instituciones universitarias católicas desde diferentes posiciones. En Italia, por ejemplo, tanto en los medios de comunicación como en la elaboración y aprobación política de la legislación y en el debate académico, han chocado con fuerza la "bioética laica" y "la bioética católica", especialmente respecto de las exigencias éticas derivadas del mensaje cristiano sobre el hombre y la vida humana.

En Latinoamérica han sido y son importantes tanto la aportación académica al desarrollo de la bioética desde instituciones católicas(5) como, también, los intentos de diálogo racional entre diversas fundamentaciones(6). 
La confrontación es clara en algunas posturas. En un trabajo conjunto sobre el humanismo en la era de la globalización, entre los institutos de Essen, en Alemania, y Morelia, de México, se evalúa el papel de la religión de un modo bastante negativo(7): "La religión siempre ha jugado un papel significativo en el proceso de construcción de las identidades culturales del hombre, pero se ha convertido hoy, por desgracia, en un preocupante obstáculo en el intento de desarrollar un sistema de valores lo suficientemente universal, de manera que este pueda llegar a tener relevancia transcultural. Debido a que la perspectiva humanista se ve acompańada frecuentemente de un modo de vida secular, el fundamentalismo religioso se opone violentamente a cualquier intento por establecer un humanismo universalista como principio regulador del entendimiento en el campo de la diversidad cultural". La religión, según esta postura, descalifica otras verdades que proclaman validez universal, como las de la ciencia o cualquier otro sistema de creencias, "...descalificando también con ello los presupuestos en que se sustenta el funcionamiento de la verdad. La única solución pareciera ser la superación de las formas específicas y peculiares del fervor religioso a favor de una moral universalista común o de un sistema ético", como la propuesta de Hans Küng(8), que mencionan los autores.

En opiniones recientes, Javier Sádaba acusa a las religiones en general, y a la católica en particular, de secuestrar el bienestar y el ideal de vida buena con las falsas garantías de su moral. La felicidad de una "sociedad laica”, a su juicio, debe estar en lo cotidiano, sin falsas esperanzas trascendentes(9).

Gianni Vattimo y Richard Rorty, desde la racionalidad hermenéutica europea y el neopragmatismo norteamericano, respectivamente, han debatido en forma reciente sobre el futuro de la religión en nuestro mundo posmoderno, caracterizado por un "pensamiento débil" que se rebela contra la violencia de cualquier dogma autoritario, tanto de la religión como de la ciencia(10): "Donde quiera que haya una autoridad que, en nombre de una comunidad científica o eclesiástica, imponga algo como verdad objetiva, la filosofía tiene la obligación de operar en la dirección contraria, para mostrar que la verdad nunca es objetividad, sino un diálogo interpersonal que tiene lugar en un lenguaje compartido (...) Si la tarea de la filosofía tras la muerte de Dios-lo cual equivale a decir tras la deconstrucción de la metafísica- consiste en volver a juntar las piezas, en volver a agruparlas, entonces la secularización es el modo más apropiado de dar testimonio de la relación que vincula a la civilización europea contemporánea con su propio pasado religioso; una relación que no comporta únicamente la superación y la emancipación, sino también la conservación"(10:16). Pero su propuesta es la conservación de un fe religiosa siempre que esta se "privatice", no de una fe religiosa "que funde iglesias y adopte posiciones políticas", pues parten del laicismo anticlerical que asume la total autonomía de la vida social, cultural y política respecto de cualquier iglesia: "la religión debe transformarse en algo privado"(10:32).

Dentro del ámbito filosófico, Diego Gracia ha escrito sobre la relevancia de las tradiciones religiosas para el discurso bioético. Expone sus conocidas tesis de la separación radical entre las éticas de la fe y las de la autonomía(11), apoyándose fundamentalmente en las obras de Rahner, Fuchs y Demmer, para concluir que los mandatos morales específicamente cristianos no pueden formularse nunca de modo absoluto y sin excepciones, pues lo único que tendría este sentido sería la "opción moral fundamental" y, por tanto, habría que avanzar hacia una autonomía religada, en el mismo sentido pero más allá del planteado por los promotores del "proyecto de ética mundial": Hans Küng y John E. Hare(12).

Esta posición es respondida desde la misma bioética por los defensores de los absolutos morales, con diferentes perspectivas filosóficas y no sólo teológicas: la opción moral fundamental-importante en el desarrollo moral personal- debe aplicarse a las acciones humanas concretas, según un esquema de valores previo a la propia opción. La opción autónoma no es la base última de fundamentación, sino la conciencia moral que aplica a lo particular y concreto los imperativos categóricos, bienes humanos básicos o valores, fundantes de la obligatoriedad moral, ya sea desde la exploración racional o desde la aceptación suprarracional -pero no irracional- de las consecuencias morales de una fe religiosa(13-15).

Desde un primer momento de confrontación, se está pasando a la convicción de que es necesario un diálogo fecundo entre bioética y religión, tendencia presente en algunas publicaciones de estos últimos años. Por una parte, en el ámbito católico se han profundizado las relaciones entre religión y ciencia(16) y entre fe y 
razón dentro del ámbito bioético(17-19), con diferentes conclusiones; por otra, como veremos, en el ámbito de la ética filosófica se ha progresado en la superación de la confrontación entre creyentes y no creyentes en nuestras plurales sociedades.

\section{La aportación de la moral católica a la bioética}

Es bien conocida la posición oficial de la Iglesia Católica, a través de la Encíclica "Fides et Ratio" de Juan Pablo II, respecto de la armonía y complementariedad de ambas(20): “...es posible reconocer, a pesar del cambio de los tiempos y de los progresos del saber, un núcleo de conocimientos filosóficos cuya presencia es constante en la historia del pensamiento. Piénsese, por ejemplo, en los principios de no contradicción, de finalidad, de causalidad, como también en la concepción de la persona como sujeto libre e inteligente y en su capacidad de conocer a Dios, la verdad y el bien; piénsese, además, en algunas normas morales fundamentales que son comúnmente aceptadas. Estos y otros temas indican que, prescindiendo de las corrientes de pensamiento, existe un conjunto de conocimientos en los cuales es posible reconocer una especie de patrimonio espiritual de la humanidad. Es como si nos encontrásemos ante una filosofía implícita por la cual cada uno cree conocer estos principios, aunque de forma genérica y no refleja. Estos conocimientos, precisamente porque son compartidos en cierto modo por todos, deberían ser como un punto de referencia para las diversas escuelas filosóficas (...) La Iglesia, por su parte, aprecia el esfuerzo de la razón por alcanzar los objetivos que hagan cada vez más digna la existencia personal. Ella ve en la filosofía el camino para conocer verdades fundamentales relativas a la existencia del hombre. Al mismo tiempo, considera a la filosofía como una ayuda indispensable para profundizar la inteligencia de la fe".

Es significativo, además, que dos de los capítulos se titulen "Credo ut intellegam" e "Intellego ut credam", esto es, creer para conocer más por la fe y razonar para llegar a fundamentar mejor la propia creencia religiosa. Por otro lado, en sus obras como filósofo, Karol Woytila ofrece un significativo aporte para la fundación de una ética racional de tipo personalista desde el diálogo con parte de la filosofía del siglo XX(21).

También desde la reflexión moral católica se realiza un esfuerzo por profundizar en el sentido del Magisterio de la Iglesia y en su interpretación desde variadas posiciones, pero siempre también desde la posibilidad de complementar fe y razón en la búsqueda de soluciones a los dilemas planteados en bioética. Elio Sgreccia señala que el aporte específico realizado (a la bioética) comprende cuestiones de método, de epistemología y de fundamentación, a partir del "personalismo cristológico" del Vaticano II y de la extensa aportación magisterial de Juan Pablo II $(22,23)$.

"Siempre se ha afirmado -comenta Javier Gafo(24)_ que las exigencias éticas no sólo tienen validez para el creyente, sino que representan los valores éticos que todo hombre, cristiano o no, tiene grabados en su conciencia”. El modelo ético de la ley natural, de carácter predominantemente deontológico, "es el mejor reflejo y exponente de esta pretensión de universalidad de la moral católica en general y, en concreto, en los temas de ética de la vida”(25), pero no es el único.

"El discurso racional ético es fundamental en una bioética 'católica'. La moral católica (...) debe utilizar también las mismas herramientas del discurso racional ético (...) Nuestra forma de percibir los valores humanos básicos y de relacionarnos con ellos está configurada por nuestra cultura y nuestra forma de ver el mundo. Esta forma de ver el mundo puede distorsionar los valores humanos básicos y afectar consecuentemente a nuestras opciones éticas. Es en este punto donde se puede inscribir el significado de la bioética cristiana. La fe ilumina al creyente para hacerle sensible a los genuinos valores humanos. La tradición cristiana ilumina esos valores, los apoya y les proporciona un contexto para saber leerlos en las circunstancias concretas de la vida; sirve para subrayar los verdaderos valores humanos contra todos los intentos culturales de distorsionarlos"(24:97).

Este sería el papel principal de la moral católica en países con o sin mayorías cristianas, aunque se pueda disentir del adjetivo de "católica" o de "cristiana" aplicado a la bioética, que es ampliamente rechazado desde muy diferentes posiciones por contradictorio $(26,27)$.

¿Cuáles serían los valores cristianos de especial relieve en bioética? Javier Gafo nos ofrece una sugestiva enumeración, la cual resumimos:

- El valor y la intrínseca dignidad de todo ser humano, por encima de las circunstancias externas y personales.

- La vida humana constituye un valor fundamental del que no se puede disponer arbitrariamente. 
- La ética de Jesús es una ética en la libertad y constituye un valor básico.

- La ética evangélica está basada en el amor, en el don gratuito, en el dar sin esperar respuesta. Tiene una marcada predilección por el pobre, por el débil, por el marginado.

- El mensaje de Jesús insiste en la esencial solidaridad humana. No es una ética individualista que prescinda de las repercusiones sociales de su quehacer, en busca de una autoperfección personal.

- La ética cristiana supone una superación de la espiral de violencia: no se vence al mal con el mal, sino con el bien.

"Todos estos valores, genuinamente evangélicos, son asumibles desde una ética no-creyente. Permiten un diálogo no sólo interdisciplinar, siempre necesario en los temas de bioética, sino también entre distintas cosmovisiones y concepciones de la vida"(24:98). Y son valores que concretan y profundizan en el principio bioético de beneficencia, que no puede ser el eterno olvidado: "La reflexión bioética cristiana tiene que seguir subrayando sus propios valores y su propio carisma, centrados especialmente en torno al principio de beneficencia: el valor del débil, la importancia de la generosidad y del altruismo, con énfasis en la relación de amistad personal sanitario-enfermo, que surgen de una ética que hunde sus raíces en el mensaje evangélico"(24:100).

\section{El aporte de la teología cristiana a la bioética}

En los últimos ańos existe un verdadero interés por señalar el aporte óptimo de la teología moral en el debate bioético, desde el diálogo constructivo(28). "La intención de fondo en todo ello -comenta Francisco J. Alarcos- no es sino estimular la búsqueda, el diálogo y la cooperación de los bioeticistas, tanto de índole secular como teológica, en la tarea ineludiblemente humana de cuidar la fragilidad vital en todas sus dimensiones" (29).

Entre los pensadores de nuestro tiempo, Hans Küng aboga por la conciliación de racionalidad y fe cristiana en una apuesta común, con su propuesta de una ética universal(8). En un nuevo libro aborda temas centrales: ¿Dios como principio? ¿Creación o evolución? ¿Es todo azar? ¿Es el libre arbitrio una ilusión? Pero no se limita a mostrar las respuestas específicas que ciencia, filosofía y teología dan a estas preguntas, sino que, superando antagonismos a menudo teñidos de ideología, se hace cargo de la luz que "sigue irradiando el testimonio de la Biblia, siempre y cuando sea entendida de forma acorde con los tiempos; luz como la que, desde la humilde confianza en sí mismas, hoy pueden transmitir a los seres humanos una filosofía y una teología ilustradas"(30).

Hans Küng hace hincapié en la apertura de cada religión a las demás y a una ética universal común, aunque otros autores priorizan como valor el mantenimiento de la propia identidad religiosa en un mundo respetuoso con la diversidad cultural.

Marciano Vidal ha estudiado en extenso estos temas, y también su relación con la bioética(31,32): "Hoy parece que estamos de acuerdo en afirmar que (...) el que cree en una moral religiosa, que haga la moral religiosa pensando como si Dios no se diera. Y el que haga una moral no religiosa que piense, por si acaso, "et si Deus daretur". Al menos por esta razón, aceptamos una moral religiosa y una no religiosa, y que convivan. El cómo queda abierto y es, en gran parte, el problema más serio de la fundamentación y de la epistemología ética y, sobre todo, de la teológica que nos afecta más en este momento" (32:26). En un reto para la propia teología católica, "cómo se constituye una epistemología teológica hoy, qué puede aportar a la racionalidad común de la humanidad y cómo se puede o se debe hacer presente hoy de forma pública y operante" (32:112). La ética religiosa debe contribur, en el aspecto metodológico, con una apertura al diálogo en el discurso bioético. En la fundamentación de la bioética, lo que debe aportar la teología católica es "una antropología integral", relacionando el horizonte de sentido con la verdad científico-técnica y ofreciendo la conexión perdida con la sabiduría tradicional(32:119).

Los principios bioéticos se entienden de manera distinta desde la fe, se jerarquizan también de otro modo y se pueden desarrollar con una profundidad diferente. Por ejemplo, la justicia o la autonomía están complementadas también por la solidaridad en la reflexión teológica(33).

Algunos autores-desde posiciones más o menos cercanas a una teología de la liberación(34) - hablan de una "filosofía de la liberación" y del papel liberador de una bioética emancipadora de Latinoamérica, en un contexto de injusticias persistentes: “....evitando caer en el individualismo, la teología latinoamericana y la bioética 
-comenta Marco Fabri dos Anjos(35) - van hacia una intersubjetividad capaz de dialogar, de ser parte de una red, de buscar y encontrar razones compartidas, compartir significados y vivirlos en la sociedad", pasando del "mero consenso al buen sentido" (36). Son voces presentes en el debate bioético latinoamericano, en Brasil y Argentina especialmente. Su raíz se encuentra en la teología católica y en la interpretación de la justicia como principio moral básico y también como filosofía primera, en el sentido que le otorga Dussel(37).

\section{La necesidad de diálogo en el ámbito de la bioética}

En el ámbito filosófico actual sobresale la necesidad de un diálogo. Desde la ética del discurso, Habermas(38) insiste en la necesidad del diálogo entre dos tendencias contrapuestas que caracterizan la situación intelectual de esta época: por un lado, la creciente implantación de "imágenes naturalistas del mundo" y, por otro, el "recrudecimiento de las ortodoxias religiosas". Habermas sondea las tensiones entre naturalismo y religión y defiende una comprensión adecuadamente naturalista de la evolución cultural, que rinda cuentas del carácter normativo del espíritu humano. Además, propone una interpretación adecuada de las consecuencias secularizadoras de una racionalización cultural y social que, de modo creciente, los defensores de las ortodoxias religiosas se resisten a aceptar como la verdadera senda histórica de Occidente.

Lo interesante de esta obra es la nueva sensibilidad con la que se aproxima al choque actual entre la fría visión que aportan las ciencias respecto de lo que es el ser humano y la imagen legada por la tradición religiosa. Habermas aboga por entrar en una sociedad "postsecular", en la cual las argumentaciones religiosas puedan competir en plano de igualdad con las explicaciones cientificistas a la hora de interpretar la vida en común.

En definitiva, la religión complementa a la filosofía, pues esta aporta lo que debemos hacer, la ética, mientras la religión aporta lo que debemos esperar: "La religión alberga los símbolos en que la humanidad ha fantaseado sus esperanzas de redención y de plenitud. En la medida en que, sin arbitrariedad, pero sin claudicaciones, se muestre la posible razonabilidad de esas esperanzas, ellas pueden dibujar un tercero entre la tentación del que delira, abandonando la realidad porque esta no se ajusta a sus deseos, y la tentación del que se resigna desconsoladamente ante ella y pretende negar el propio deseo porque cree que no se va a cumplir" (39).

Un doble reto de contribución y aprendizaje se plantea desde la bioética a la religión y viceversa. La tensión entre ciencias y religiones se acentúa cuando ambas se convierten en ideologías, por lo que la filosofía, crítica frente a ambas, puede y debe mediar en la discusión, hoy más que nunca. Las controversias de bioética se bloquean a veces por la presión de intereses políticos y prejuicios religiosos. Hay que recuperar, desde la filosofía, la capacidad dialogante de una bioética construida como conversación y en un doble nivel: los debates interdisciplinares académicos y el diálogo cívico en el seno de una sociedad plural y democrática(40). Porque sabemos que "no existe incompatibilidad entre una bioética laica y la ética de las religiones, entre la revolución biogenética y las religiones. Para ello es necesario que las religiones cambien de paradigma y lenguaje. Religiones, bioética y biogenética tienen que caminar a la par con sentido crítico y autocrítico, sin desconocerse, pero sin entorpecerse" (41).

Sin embargo, también es necesaria una apertura desde la neutralidad religiosa del Estado actual: "Durante las últimas décadas, muchos acontecimientos nos obligaron a reconsiderar no los fundamentos de la separación entre la política y la religión, sino determinados aspectos de su institucionalización. El papel de la religión dentro del espacio público y, en consecuencia, el significado del ideal de neutralidad religiosa en lo que Habermas ha dado en llamar 'sociedad postsecular', parecen requerir un examen más detenido"(42). "La demanda, tanto dentro como fuera de las sociedades democráticas occidentales, de que la fe religiosa tenga un papel más público, o al menos de que sea desprivatizada, merece ser considerada y nos obliga a atender a tres cuestiones: el logro de la total igualdad entre los ciudadanos creyentes y no creyentes; el diferente ritmo en el que evolucionan la conciencia religiosa y la secular, y la diferencia antropológica entre las diversas formas de religiosidad para adaptarse a la separación entre la Iglesia y el Estado"(41:35).

Es necesaria una "laicidad plural consistente con las implicaciones de un Estado laico, pero capaz de gestarse y sostenerse desde tradiciones culturales y religiosas diversas", de forma que debemos "pensar la religión para repensar la laicidad”, en términos de interculturalidad(42). 
En sociedades pluralistas como las nuestras, cada vez más multiculturales, en las que debemos actuar según un principio de justicia, "la vía para ello no puede atascarse en poner entre paréntesis las convicciones particulares acerca del sentido y de los valores en que se encarna -hasta que salten, señalando el tope de lo tolerable desde ellas-, sino que ha de situarse la "verdad moral" de la exigencia de justicia como horizonte de sentido que todos pueden compartir como marco de los acuerdos posibles. Sólo así es posible que cuaje socialmente, desde los individuos, una responsabilidad solidaria efectiva y universalistamente abierta, más allá de los intereses del 'nosotros' inmediato"(43).

Antes de este debate actual sobre la globalización y el choque de civilizaciones, y después de analizar las relaciones entre la filosofía y la especificidad del lenguaje religioso, y el reto que supone para ambas la existencia del mal, Ricoeur hacía hincapié en el carácter hermenéutico común a la fe bíblica y a la filosofía(44): "Es perfectamente inútil oponer Jerusalén a Atenas. Es por ello que la inteligencia de la fe (...) no puede no integrar los instrumentos reflexivos e intelectuales que debe a esta cultura de origen griego. En este sentido, es en su mismo seno que una fe pensante debe continuar el diálogo de la representación y el concepto".

En definitiva, se ha reiniciado definitivamente $-y$ a ello ha aportado también el desarrollo de la bioéticael diálogo entre fe y razón, entre religión y ciencia, más allá de los extremismos propios de la sociedad posmoderna y secularista del siglo XX y de las posiciones intolerantes más ideológicas que religiosas. En la confrontación se pierden de vista las razones del otro y se intenta construir un mundo a la medida de nuestras personales razones excluyentes. La historia del cristianismo es la historia de un diálogo fructífero entre fe y razón, superador de ideologías irracionales. En el diálogo, al entender y respetar -aunque no se compartan- las razones del otro, entenderemos también mejor nuestras propias ideas y podremos ofrecer entre todos soluciones positivas en un mundo necesitado de clarificación y profundización en los valores morales. La reflexión bioética -a través del diálogo- puede aportar mucho a esta tarea en este siglo XXI marcado por el multiculturalismo y los choques entre civilizaciones y culturas religiosas.

\section{Referencias}

1. Beauchamp TL, Childress JF. Principios de ética biomédica. Barcelona: Masson; 1999: 33-36.

2. Charlesworth M. La Bioética en una sociedad liberal. Cambridge: Cambridge University Press; 1996: 1-10.

3. Engelhardt HT. Los fundamentos de la bioética. Barcelona: Paidós Ibérica; 1995: 104-105.

4. García Capilla DJ. El nacimiento de la bioética. Madrid: Biblioteca Nuova; 2007.

5. Fe y Ciencias. Jornada del 8 de octubre de 1997. Buenos Aires: Ediciones de la Universidad Católica Argentina; 1998.

6. Pessini L, Paul de Barchifontaine ChP, Lolas F. (coords.) Perspectivas de la bioética en Iberoamérica. Santiago de Chile: Cieb y Programa de Bioética OPS; 2007.

7. Rüsen J, Kozlarek O. (coord.) Humanismo en la era de la globalización. Desafios y perspectivas. Buenos Aires: Editorial Biblos; 2009: 23-24.

8. Küng H, Rinn-Maurer S. La ética mundial entendida desde el cristianismo. Madrid: Trotta; 2008.

9. Sádaba J. La vida buena. Cómo conquistar nuestra felicidad. Barcelona: Península; 2009: 39-52.

10. Rorty R, Vattimo G. El futuro de la religión. Solidaridad, caridad e ironía. Barcelona: Paidós; 2006: 25.

11. Gracia D. Religión y ética. En: Como arqueros al blanco. Estudios de bioética. Madrid: Triacastela; 2004: 129-196.

12. Gracia D. Fundamentaciones de la bioética. En: Juan Vélez (coord.) Bioéticas para el siglo XXI. 30 años de bioética (19702000). Bilbao: Universidad de Deusto; 2003: 31-55.

13. Laun A. La conciencia. Barcelona: EIUNSA; 1993.

14. Finnis J. Cuestiones de ética. Barcelona: EIUNSA; 1992.

15. Pérez-Delgado E. Moral de convicciones, moral de principios. Una introducción a la ética desde las ciencias humanas. Salamanca-Madrid: EDIBESA; 2000.

16. Dou A. (ed.) Pensamiento cientifico y trascendencia. Madrid: Universidad Pontificia de Comillas; 1998.

17. Gafo J. (ed.) Bioética y religiones: el final de la vida. Madrid: Universidad Pontificia de Comillas; 2000. 
Bioética y religión cristiano-católica: dos racionalidades complementarias - Francisco Javier León Correa

18. Varios autores. Bioética, religión y derecho: actas del curso de verano de la Universidad Autónoma de Madrid, celebrado en Miraflores de la Sierra del 14 al 16 de julio de 2005. Madrid: Fundación Universitaria Española; 2005.

19. Kottow M, Anguita V. Bioética católica. Márgenes de interpretación de las enseñanzas magisteriales. Santiago de Chile: CINBIO; 1995.

20. Juan Pablo II. Encíclica Fides et Ratio. Ciudad del Vaticano: Santa Sede; 1998.

21. Wojtyla K. Mi visión del hombre. Hacia una nueva ética. Madrid: Ediciones Palabra; 1997.

22. Sgreccia E. Aportes de la Iglesia Católica al desarrollo de la bioética. Ars Medica, Santiago de Chile, 2008; 16: 215230.

23. Herranz G. Some Christian Contributions to the Ethics of Biomedical Research. A Historical Perspective. En: Vial Correa J, Sgreccia E. The Ethics of Biomedical Research. A Christian View. Proceedings of the Ninth General Assembly of the Pontifical Academy for Life. Vatican City, Rome; 2003.

24. Gafo J. Bioética y Tradición Católica. En: Vélez J (coord.) Bioéticas para el siglo XXI. 30 años de bioética (1970-2000). Bilbao: Universidad de Deusto; 2003: 79-110.

25. Flecha JR. Teología moral fundamental. Madrid: BAC; 1994: 135-138.

26. Lolas F. Bioética y antropología médica. Santiago de Chile: Mediterráneo; 2003: 47-48.

27. Guerra R. Por una bioética sin adjetivos en el contexto de la crisis moderno-ilustrada. Medicina y Ética 2007; 18(2): 133-149.

28. Bochatey A. Bioética y teología moral. Buenos Aires: Ediciones Paulinas, Pontificia Universidad Católica Argentina; 1994.

29. Alarcos FJ. Bioética global, justicia y teología moral. Bilbao: Desclée de Brouwer; 2005.

30. Küng H. El principio de todas las cosas. Ciencia y religión. Madrid: Trotta; 2007.

31. Vidal M. Orientaciones éticas para tiempos inciertos. Entre la Escila del relativismo y la Caribdis del fundamentalismo. Bilbao: Desclée de Brouwer; 2007.

32. Vidal M. Ética cristiana y toma de decisiones en Bioética. En: Vélez J. (coord.) Bioéticas para el siglo XXI. 30 años de bioética (1970-2000). Bilbao: Universidad de Deusto; 2003: 111-122.

33. De Velasco JM. La bioética y el principio de solidaridad. Una perspectiva desde la ética teológica. Bilbao: Universidad de Deusto; 2003.

34. Boff L. A voz do Arco-Iris. Brasilia: Letraviva Editorial; 2000.

35. Dos Anjos MF. Bioética y religión en América Latina. En: Pessini L, Paul de Barchifontaine Ch, Lolas F. (coords.) Perspectivas de la bioética en Iberoamérica. Santiago de Chile: Cieb y Programa de Bioética OPS; 2007: 219-232.

36. Moser A, Soares AM. Bioética. Do consenso ao bom senso. Petrópolis: Editora Vozes; 2006.

37. Dussel E. Ética de la liberación en la edad de la globalización y de la exclusión. Madrid: Trotta; 2008.

38. Habermas J. Entre naturalismo y religión. Barcelona: Paidós; 2006.

39. Gómez Sánchez C. Problemas éticos en la religión. En: Guariglia O. (ed.) Cuestiones morales. 1a reimp. Madrid: Trotta; 2007.

40. Masiá J. Bioética y religión. Barcelona: Síntesis; 2008.

41. Tamayo JJ. Bioética y religión. Madrid: Dykinson; 2007.

42. Ferrara A. La religión dentro de los límites de la razonabilidad. En: La fuerza del ejemplo. Exploraciones del paradigma del juicio. Barcelona: Gedisa Editorial; 2008: 245-267.

43. Pérez Tapias JA. Del bienestar a la justicia. Aportaciones para una ciudadanía intercultural. Madrid: Editorial Trotta; 2007: 87.

44. Ricoeur P. Fe y filosofia. Problemas del lenguaje religioso. Buenos Aires: Editoriales Alnagesto y Docencia, 2a ed.; 1994: 221-229.

Recibido: 18 de enero de 2010

Aceptado: 12 de marzo de 2010 